DOI 10.17150/978-5-7253-3001-4.22

И.В. ОРЛОВА

УДК 614.4(091)(571.53)

ББК 5г(5Рос-4Ирк)

\title{
ИСТОРИЯ РАЗВИТИЯ \\ САНИТАРНО-ЭПИДЕМИОЛОГИЧЕСКОЙ СЛУЖБЫ ИРКУТСКОЙ ОБЛАСТИ
}

В статье рассматриваются этапы развития санитарно-эпидемиологической службы Иркутской области. Дается основная характеристика направлений деятельности на каждом этапе, приводятся статистические данные.

Ключевые слова: санитарно-эпидемиологическая служба, Иркутская область, инфекционные заболевания, профессиональные заболевания, санитарно-гигиенические исследования. 


\section{HISTORY OF DEVELOPMENT \\ OF SANITARY AND EPIDEMIOLOGICAL SERVICES OF THE IRKUTSK REGION}

The article discusses the stages of development of the sanitary-epidemiological service of the Irkutsk region. The main characteristic of activities at each stage is given, statistical data are presented.

Keywords: sanitary-epidemiological service, Irkutsk region, infectious diseases, occupational diseases, sanitary-hygienic studies.

Развитие санитарного дела в Иркутской области на систематической и научной основе началось после Гражданской войны. В этот период вся полнота власти была передана губернскому революционному комитету, при котором был создан отдел здравоохранения с подотделами: коммунальный, военно-санитарный, санитарно-статистический, водно-санитарный.

Санитарное состояние региона в тот период было критическим. Последствия революционных событий и Гражданской войны стали причиной охвата всей территории Иркутской губернии такими острыми инфекционными заболеваниями как, туберкулез, сифилис, эпидемии сыпного и возвратного тифов. Сеть медицинских учреждений была развита слабо, а санитарную службу предстояло создавать заново. 15 сентября 1922 г. был подписан Декрет «О санитарных органах Республики», который подтвердил государственный характер санитарно-эпидемиологической службы, определил ее задачи, структуру и нормы, права и обязанности. Эта дата считается официальной датой создания государственной санитарно-эпидемиологической службы в России. Если в период 1922-1925 гг. проводились в основном противоэпидемические и общие санитарные мероприятия (обследования медицинские осмотры различных групп населения, очистка источников водоснабжения, очистка придомовых территорий и улиц), увеличивался штат врачей, создавался актив из населения [2, с. 117]. То в конце 1920-х гг. санитарные мероприятия начинают принимать более планомерный характер. Так, на ведущих промышленных предприятиях Иркутска, Усолье-Сибирского, Черемхово начинается изучение условий труда и быта рабочих, наряду с медицинскими осмотрами внедряются мероприятия по диспансеризации рабочих. Санитарно-гигиенические исследования в этот период получили прикладное значение - начинается реконструкция старых и строительство новых промышленных, общественно-бытовых и социально-культурных объектов. Наряду с образованием государственной санитарной инспекцией в городах и районах области устанавливаются 
должности госсанинспекторов, организуются санэпидстанции, бактериологические и санитарно-гигиенические лаборатории, растет число работающих в них врачей и помощников.

В период 1930-х гг. структура, штат санитарно-эпидемиологических учреждений и их мероприятия были продиктованы эпидконъюктурой региона. В 1930 г. в Иркутском медицинском институте был образован санитарно-гигиенический факультет. Первый выпуск врачей-эпидемиологов (а их было 44 человека) состоялся в 1935 г. - это была первая волна профессионалов, подготовленных для региона с его конкретными особенностями и запросами. Эти дипломированные специалисты первых выпусков санитарно-гигиенического факультета мединститута были призваны возглавить вновь образованные учреждения. Ярким примером тому служит карьера Т.И. Истоминой, врача-гигиениста первого выпуска санитарно-гигиенического факультета Иркутского медицинского института [3, с. 108]. В 1938 г. Т.И. Истоминой была организована районная санэпидстанция в Тайшете, а в 1960-е гг. Истомина стала главным эпидемиологом Иркутской области.

Так, в 1937 г. в Иркутской области работало 11 санитарно-эпидемиологических учреждений, в том числе 3 малярийных пункта, 2 самостоятельные санбаклаборатории, 2 дезинфекционные станции, 2 санпропускника, Пастеровская станция. В этих учреждениях было 98 врачебных должностей и 149 должностей среднего медицинского персонала, в том числе 38 госсанинспекторов и 47 их помощников, 3 врача-маляриолога, 2 врача-бактериолога, 7 врачей-эпидемиологов и 31 санитарный врач [5, с. 7].

Так, в 1931 и 1933 гг. в Иркутской губернии были зафиксированы эпидемические вспышки брюшного и сыпного тифов. На ликвидацию этих заболеваний были сорормированы противоэпидемические отряды, и хотя к концу 1933 г. Вспышки заболеваний были ликвидированы, ситуация оставалась серьезной, а показатели заболеваемости тифом оставались высокими еще долгое время. В 1939 г. показатель в Иркутской области по сытному тифу на 100000 населения составлял 17,4; дифтерией - 82,0; брюшным тифом - 70,0; малярией - 692,5. Угрожающий характер носили показатели по таким детским инфекциям как дифтерия, скарлатина, корь, коклюш. К концу 1930-х гг. возросло число санитарно-эпидемиологических учреждений с 11 до 24, была организована областная малярийная станция, санитарно-гигиеническая лаборатория, промышленно-санитарная лаборатория [6, с. 136]. Число врачебных должностей увеличилось с 98 до 149, но укомплектованность ими была лишь на 65 \%.

Показательна статистика санитарно-бактериологической лаборатории за 1937 г. Так, было выполнено 9155 эпидемиологических анализов, 7231 санитарно-гигиенических исследований. При этом из общего количества санитарно-гигиенических исследований 70 \% со- 
ставляли анализы пищевых продуктов (в том числа молока и мяса на колхозных рынках) и 30 \% анализ воды (бактериологический и краткий химический анализ воды из водопровода, водоемом в пунктах водопользования и колодцев). Что касается эпидемиологических анализов, то проводились они с целью диагностики инфекционных заболеваний, задачи исследований данных анализов с профилактической точки зрения в данный период не реализовывались.

Статистика 1937 г. также содержит сведения о том, что на Пастеровской станции прошли курс антиробических прививок 160 человек; были подвергнуты штрафам 1502 человека, возбуждено 25 судебных дел, закрыто 39 предприятий, оформлено 398 заключений пищевого бракеража, т.е. оценка качества приготовленной пищи по внешнему виду, вкусу и запаху [5, с. 7].

В период Великой Отечественной войны (1941-1945) санитарно-эпидемиологические станции, главным образом, занимались вопросами текущего санитарного надзора за условиями промышленных предприятий тыла, контролем санитарного состояния предприятий общественного питания, детских учреждений, за качеством водоснабжения населения, проведением противоэпидемических заболеваний особенно в условиях перманентной миграции раненных и эвакуированных из западных регионов страны. Следует отметить, что за военный период инфекционные заболевания в Иркутской области не получили широкого распространения, а сеть санитарно-эпидемиологических учреждений увеличивалась. Об этом свидетельствуют следующие факты: в 1940 г. в области было 26 санэпидучреждения, в 1945 г. их было уже 43, возросло и количество врачебных должностей до 163, а число среднего медицинского персонала увеличилось до 337. В 1944 г. была организована областная санэпидстанция со штатом 9 врачей и 11 медработников [2, с. 113].

Наибольшее количество санэпидстанций в Иркутской области пришлось на начало 1950-х гг. В 1952 г. работало 48 санэпидстанций и санэпидучреждений (кроме этих учреждений были самостоятельные санэпидучреждения такие как областная госсанинспекция, малярийная, бруцеллезная и дезинфекционные станции и дом санитарного просвещения). Самой крупной из них была Иркутская городская СЭС (110 штатных единиц), вторая по численности была Иркутская дезостанция (80 штатных единиц), Черемховская городская СЭС насчитывала 46 штатных единиц. Однако, укомплектованность штатов не была полной, в двух указанных учреждениях областного центра при штате в 190 единиц физических лиц было только 140. Но главной проблемой в работе всех санэпидучреждений была низкая укомплектованность транспортными средствами. Из 48 учреждений только 6 обладали автомобилями, 12 располагали гужевым транспортом, остальные не имели никаких транспортных средств [4, с. 27]. 
Этот период характеризуется усилением развития лабораторного дела, в Иркутской области уже функционировало 19 санбаклабораторий, к 1953 г. было подготовлено открытие еще 8 баклабораторий. Санэпидстанции приступили к изучению заболеваемости рабочих ведущих отраслей промышленности, а также профессиональной заболеваемости региона. Большая работа проводилась по снижению заболеваемости силикозом на предприятиях треста «Мамслюда», куда ежегодно направлялись комплексные бригады по изучению условий труда рабочих и проведению периодических медицинских осмотров. По результатам работы этих бригад разрабатывались комплексные планы оздоровительных мероприятий, в результате, который снизилась заболеваемость силикозом.

Огромную роль на последующую деятельность учреждений санэпидслужбы оказало принятое на XIII съезде гигиенистов, эпидемиологов, инфекционистов, микробиологов СССР, проходившем в 1956 г., решение о целесообразности объединения функций предупредительного и текущего санитарного надзора и передачу всех фрункций санитарноэпидемиологическим станциям.

В 1960-х гг. санитарно-эпидемиологическая служба Иркутской области представляла стройную систему учреждений и направлений работы, включающих не только ликвидацию и резкое снижение инфекционных заболеваний, охране водоемов и атмосферного воздуха, по улучшению условий труда и быта, но и физического развития детей и подростков, вопросы гигиены питания. В 1965 г. в Иркутской области сеть санитарно-эпидемиологических учреждений состояла из 32 СЭС, 1 дезостанции, дома санитарного просвещения, станции по борьбе с гнусом. Кроме этого были созданы линейные санэпидстанции на ВСЖД, а также санэпидстанции в системе гражданской авиации. Уменьшение количества станций связано с укрупнением районов. В 1966 г. промышленными лабораториями было проведено более 15 тыс. исследований (освещенности, загазованности, запыленности, шума, вибрации, метеофакторов) на промышленных предприятиях области. В том же году была организована радиологическая группа в областной санэпидемстанции, которой за первый год существования было проведено 537 радиохимических исследований на стронций и цезий, 7200 дозиметрических измерения в рентген-кабинетах, 126 определений суммарной активности атмосферного воздуха, 240 на активность загрязнений поверхностях.

1960-е гг. для санитарно-эпидемиологической службой можно охарактеризовать как период комплексной реализации задач санитарного благоустройства, санитарно-технических и архитектурно-планировочных мероприятий в отношении новых городов. В этот период санитарно-эпидемиологическая служба стала центром гигиенической и эпидемиологической диагностики и оздоровления населения, однако, устранение неблагоприятных последствий военного времени, гигиенические проблемы 
выдвигали новые, не менее трудные к разрешению задачи. Значительна роль службы по контролю и пуском в эксплуатацию гидроэлектростанций, промышленных предприятий Иркутской области. Развитие лабораторной службы, увеличение объема исследований среды обитания человека позволило применять обоснованные требования к руководителям предприятий по внедрению природоохранных мероприятий, строительству водоочистных и газопылеулавливающих установок, в обеспечении доброкачественными продуктами питания и питьевой водой.

Начиная с 60-70-х гг. XX в. в целях совершенствования обеспечения санитарно-эпидемиологического благополучия, получают дальнейшее развитие санитарно-эпидемиологические станции с оперативными подразделениями.

Социально-экономическая ситуация в стране оказала огромное влияние на здоровье населения, его санитарно-эпидемиологическое благополучие. Восточная Сибирь в 1970-е гг. имела статус индустриально-промышленного региона страны. В Иркутской области были сконцентрированы крупнейшие предприятия целлюлозно-бумажной, металлургической, нефтехимической и химической промышленности, что с одной стороны было источником экономической стабильности, с другой источником загрязнений окружающей среды региона. В этих условиях проблемы обеспечения санитарно-эпидемиологического благополучия населения приняли приоритетное направление.

В новый период - период «перестройки», в сорере обслуживания, общепита, торговли, наряду с государственными, появились частные структуры, куда пришли работать немало случайных людей, непрофессионалов. Именно в это время потребовалось усиление контроля за соблюдением санитарных требований, состоянием производственного лабораторного контроля за выпускаемой продукцией, гигиенического обучения новых декретированных групп, усиления санитарного просвещения.

В 1991 г. открыта новая страница в истории санитарно-эпидемиологической службы России. 19 апреля 1991 г. был принят закон Российской Федерации «О санитарно-эпидемиологическом благополучии населения». Таким образом, на законодательном уровне было введено регулирование общественных отношений в сфере обеспечения санитарно-эпидемиологического благополучия населения, создана единая централизованная федеральная система. Этим законом служба была переведена на уровень централизованного управления с подчинением нижестоящих учреждений вышестоящим и централизованным финансированием из федерального бюджета.

В 2000-х гг., в период реализации административной и бюджетной реформ, проводимых правительством Российской Федерации, основные направления деятельности службы были связаны с совершенствованием и повышением эффективности государственного санитарно- 
эпидемиологического надзора и нового надзора в сфере защиты прав потребителей. С этой целью в 2005 г. была проведена реорганизация и формирование новой структуры службы, создана единая система органов и учреждений - Федеральная служба по надзору в сфере защиты прав потребителей и благополучия человека (Роспотребнадзор). Новая структура службы была создана и в Приангарье: Управление Федеральной службы по надзору в сфере защиты прав потребителей и благополучия человека по Иркутской области (Управление Роспотребнадзора по Иркутской области) с территориальными отделами в городах и районах области и Федеральное бюджетное учреждение здравоохранения «Центр гигиены и эпидемиологии в Иркутской области» с филиалами.

Одним из важных итогов этих преобразований явилось, то, что удалось сохранить систему государственного санитарно-эпидемиологического надзора, которая представляет собой единую фредеральную централизованную службу с высокопрофессиональным кадровым потенциалом, мощной лабораторной базой. В этот период реализация полномочий службы переходит на качественно новый уровень. Новое законодательство полностью меняет идеологию проведения контрольных (надзорных) мероприятий. С одной стороны законодательство определяет не препятствовать развитию бизнеса, а с другой стороны защищать права граждан на гарантированную безопасность товаров и услуг.

В настоящее время на территории Иркутской области фредеральный государственный санитарно-эпидемиологический надзор и надзор в сфере защиты прав потребителей осуществляют и обеспечивают Управление Роспотребнадзора по Иркутской области (Управление) с 13 территориальными отделами и ФБУЗ «Центр гигиены и эпидемиологии в Иркутской области» (ФБУЗ) с 13 филиалами. Кроме того, на территории Иркутской области осуществляют государственный надзор на специальных объектах: Восточно-Сибирский территориальный отдел Управления Роспотребнадзора по железнодорожному транспорту; Восточно-Сибирский фрилиал ФБУЗ «Центр гигиены и эпидемиологии по железнодорожному транспорту»; Межрегиональное управление № 51 ФМБА России; Центр Госсанэпиднадзора МСЧ МВД России по Иркутской области; Отделение ГСЭН (территориальный г. Иркутск) ФГКУ 1026 ЦГСЭН Минобороны России; ГУФСИН России по Иркутской области; филиал ФКУЗ «Центр гигиены и эпидемиологии ФСИН России по СФО в Иркутской области». Научное сопровождение обеспечивает Иркутский ордена Трудового Красного знамени научно-исследовательский противочумный институт Сибири и Дальнего Востока.

На современном этапе, на контроле Управления Роспотребнадзора по Иркутской области находится более 40 тыс. объектов надзора во всех сферах экономики. Для реализации своих полномочий по обеспечению 
санитарно-эпидемиологического благополучия населения и защиты прав потребителей Управление Роспотребнадзора по Иркутской тесно взаимодействует с органами законодательной и исполнительной власти Иркутской области, органами местного самоуправления, различными ведомствами и службами как областного, так и федерального подчинения, общественными организациями.

Пройдя все ступени развития, преодолев многие сложности на своем пути, сегодня санитарно-эпидемиологическая служба стала самостоятельным федеральным органом исполнительной власти, осуществляющим не только федеральный государственный санитарно-эпидемиологический надзор, но и федеральный государственный надзор в области защиты прав потребителей, обеспечивая не только безопасность товаров (работ, услуг), но и их надлежащее качество. Немаловажным фрактором в этом вопросе является то, что Иркутская область имеет возможность пополнять ряды учреждений санэпиднадзора «собственными» кадрами - выпускниками Иркутского государственного медицинского университета. Как говорилось выше, первый выпуск врачей-гигиенистов состоялся в 1935 г. в количестве 44 человек. На современном этапе выпускники медико-профилактического факультета ИГМУ имеют 100 \%-е трудоустройство, выпускники распределяются не только по Иркутской области, но и в республики Бурятия, Саха, Хакассия, Тыва, Амурскую область, Красноярский и Забайкальский края [1, с. 53]. С указанными субъектами РФ у ИГМУ заключены договоры на целевую подготовку специалистом. Так, ежегодно на медико-профилактический фракультет выделяется по целевым договорам от регионов до $60 \%$ мест [7, с. 13].

История службы области на всех этапах ее развития связана с решением государственных задач - борьба с эпидемиями, преодоление последствий войн, профилактика инфекционных и массовых неинфекционных заболеваний, обеспечение надлежащих условий жизни, труда и отдыха населения. В условиях экономических и социальных преобразований в российском обществе основным показателем работы службы является стабильная санитарно-эпидемиологическая обстановка и решение актуальных проблем в сфере защиты прав потребителей.

\section{Список использованной литературы и источников}

1. Белых А. И. Современные тенденции развития образовательного процесса на медико-профилактическом фракультете Иркутского государственного медицинского университета / А. И. Белых, И. Г. Погорелова, М. О. Потапова // Система менеджмента качества: опыт и перспективы. - 2018. - Вып. 7. - С. 50-55.

2. Вендрих Г. А. Иркутск: очерки по истории города. / Г. А. Вендрих, Г. А. Кудрявцев. - Иркутск : Вост.-Сиб. кн. изд-во, 1971. - 436 с.

3. Гайдаров Г. М. Факультетские клиники Иркутского государственного медицинского университета (1920-2010). / Г. М. Гайдаров, А. Г. Шантуров, С. Н. Смир- 
нов. - 3-е изд., перераб. и доп. - Иркутск : Издание ООО «Областная типография № 1 », 2010. - 376 с.

4. К истории развития здравоохранения Иркутской области : Научные труды / А. И. Никитин. - Вып. 93. Ч. 1. - Иркутск, 1968. - 156 с.

5. К истории развития здравоохранения Иркутской области : Научные труды / А. И. Никитин. - Вып. 94. Ч. 2. - Иркутск, 1968. - 140 с.

6. Орлова И. В. Состояние медицинских учреждений иркутского региона в 1920-е гг. / И. В. Орлова // Актуальные вопросы здоровья населения и развития здравоохранения на уровне субъекта Российской Федерации : материалы Всеросс. науч.-практ. конф., посв. 155-летию образования Общества врачей Восточной Сибири (1863-2018). - Иркутск : ИГМУ, 2018. - Т. 1. - С. 135-138.

7. Щербатых А. В. Целевая подготовка медицинских кадров для здравоохранения Иркутской области / А. В. Щербатых // Система менеджмента качества: опыт и перспективы. - Иркутск : ИГМУ, 2017. - Вып. 6. - С. 12-15.

\section{Информация об авторе}

Орлова Ирина Вячеславовна - кандидат исторических наук, доцент, кафедра общественного здоровья и здравоохранения, Иркутский государственный медицинский университет, 660003, г. Иркутск, ул. Красного Восстания, 1; e-mail: irina_orlova7@mail.ru

\section{Author}

Irina V. Orlova - PhD in History, Associate Professor, Department of Public Health and Health Care, Irkutsk State Medical University, 1 Krasnogo Vosstania St., 660003, Irkutsk, Russia; e-mail: irina_orlova7@mail.ru 